УДК 69

DOI $10.21661 / \mathrm{r}-470369$

\title{
A.A. Фатьянова
}

\section{ПОСТРОЕНИЕ АВТОМАТИЗИРОВАННОЙ СИСТЕМЫ НА БАЗЕ}

\section{ПЛАТФОРМЫ 1С: ПРЕДПРИЯТИЕ С ИСПОЛЬЗОВАНИЕМ ФOPMATA JSON}

Аннотация: в статье рассматривается варианты применения формата JSON для использования при интегращии со сторонними приложениями. Предлагается использовать автоматизированные системы на базе платформы $1 C$ : Предприятие в параллельном режиме.

Ключевые слова: формат JSON, платформа 1C: Предприятие, публикачия события, сервер, клиент.

\section{A.A. Fat'yanova}

\section{CONSTRUCTION OF THE AUTOMATED SYSTEM ON THE BASIS OF THE PLATFORM 1C: ENTERPRISE USING THE JSON FORMAT}

Abstract: options of JSON format using to apply it to integrate with third-party applications is discussed in the article. It is offered to use automated systems on platform 1C Enterprise in a parallel mode.

Keywords: JSON format, platform 1C: Enterprise, event publishing, server, client.

В настоящее время для управления документацией в организациях применяются автоматизированные системы документооборота. Создание такой системы или доработка существующих систем для осуществления возможности документооборота является одной из сложнейших задач автоматизации, поскольку документооборот объединяет структурные подразделения и их бизнеспроцессы внутри объекта автоматизации и вне объекта, например передача данных о студентах в портал обучающей системы [6]. Так разработка и локальное использование документооборота рассматривалось в работах [4; 5], однако в современных автоматизированных системах на ряду с документооборотом остро 
стоит вопрос о многопользовательском использовании информационных систем и интеграции этих систем в уже существующие решения.

В данной статье рассмотрим систему, которая представлена на российском рынке: «система программ «1С: Предприятие 8» включает в себя платформу и прикладные решения, разработанные на ее основе, для автоматизации деятельности организаций и частных лиц, платформа не является программным продуктом для использования конечными пользователями, которые обычно работают с одним из многих прикладных решений (конфигураций), разработанных на данной платформе, поэтому такой подход позволяет автоматизировать различные виды деятельности, используя единую технологическую платформу» [2]

1C: Предприятие является лидером рынка в России. Технология «1С: Предприятие 8» состоит из двух частей: платформы 1С: Предприятие и 1С прикладных решений. Прикладные решения разрабатываются компанией $1 \mathrm{C}$ и их партнерами и открыты для модификации любым разработчиком в основном, но авторы решения могут закрыть некоторые модули. Программное обеспечение используется десятками тысяч российских корпораций. Платформа $1 \mathrm{C}$ : Предприятие позволяет разрабатывать бизнес-ориентированные приложения. Программное обеспечение позволяет работать с толстыми, тонкими и веб-клиентами. Он также поддерживает создание мобильных приложений для Android и iOS в одной среде с использованием языка программирования 1С.

JSON (JavaScript Object Notation) текстовый формат обмена данными широко используется в веб-приложениях. Данный формат в сравнении с XML является более компактным, средства для работы с форматом JSON имеют все браузеры.

Прикладные решения 1C: Предприятия позволяют использовать данный формат для интеграции со сторонними приложениями, такими как: «обмен файлами JSON с внешними системами; использование файлов JSON для обмена данными между разными приложениями 1С: Предприятия; организация собственного НТТР интерфейса прикладного решения;. интеграция с внешними 
системами через их НTTP интерфейсы: Google Calendar, Salesforce.com, REST интерфейс 1C: Предприятия, SharePoint и т. д.» [3].

В данной статье рассматриваем концепт автоматизированной системы и серверного приложения на базе Apache Camel для агрегации событий, происходящих в системе.

Приложение позволяет производить использование системы в параллельном режиме. При запуске приложения, получение данных происходит с сервера $1 \mathrm{C}$, затем приложение подписывается на обновление сервера публикаций. В случае изменений в базе данных, происходит публикация события и все активные пользователи получают обновления.

Сервер публикаций не зависит от количества пользователей и может производить работу автономно, при этом он является независимым узлом. При отключении системы 1С или выхода ее из строя, сервер продолжают работу и может выполнять технические части.

Главная проблема актуальности данных решается с помощью сервера публикаций. Пользователь после запуска клиентской части всегда имеет актуальные данные. При этом взаимодействия происходит непосредственно с сервером приложений $1 \mathrm{C}:$ Предприятие. В системе созданы следующие объекты.

Справочник «Группы» хранит информацию о группах, зарегистрированных в системе (таблица 1).

Таблица 1

Описание справочника «Группы»

\begin{tabular}{|l|l|l|}
\hline \multicolumn{1}{|c|}{ Имя } & \multicolumn{1}{|c|}{ Тип } & \multicolumn{1}{c|}{ Описание } \\
\hline Группа & Табличная часть & Описание студентов в группе \\
\hline Форма элемента & Форма & Добавление групп \\
\hline
\end{tabular}

Справочник «ФизЛица» хранит информацию о студентах, зарегистрированных в системе (таблица 2). 
Описание справочника «ФизЛица»

\begin{tabular}{|l|l|l|}
\hline \multicolumn{1}{|c|}{ Имя } & \multicolumn{1}{c|}{ Tun } & \multicolumn{1}{c|}{ Onисание } \\
\hline Имя & Табличные части & ФИО студента \\
\hline Форма Элемента & Форма & Форма для заведения новых студентов \\
\hline Дата Рождения & Реквизиты & Информация о дате рождения студента \\
\hline
\end{tabular}

Справочник «Права пользователей» хранит информацию о правах пользователей системы (таблица 3).

Описание таблицы «Права пользователей»

\begin{tabular}{|l|l|l|}
\hline \multicolumn{1}{|c|}{ Имя поля } & \multicolumn{1}{|c|}{ Тип данных } & \multicolumn{1}{c|}{ Описание } \\
\hline Права & Табличная часть & Описание прав \\
\hline Форма элемента & Форма & Добавление прав \\
\hline
\end{tabular}

Справочник «Студенты» хранит информацию о студентах, поступивших на обучение в учебный центр (таблица 4).

Таблица 4

Описание таблицы «Студенты»

\begin{tabular}{|l|l|l|}
\hline \multicolumn{1}{|c|}{ Имя поля } & \multicolumn{1}{|c|}{ Тип данных } & \multicolumn{1}{c|}{ Описание } \\
\hline Студенты & $\begin{array}{l}\text { Табличная } \\
\text { часть }\end{array}$ & Описание студентов в группе \\
\hline Форма элемента & Форма & Добавление студента \\
\hline Ссылка группа & Ссылка & Ссылка Описание студентов в группе \\
\hline Ссылка ФизЛица & Ссылка & Ссылка ФИО студента \\
\hline Ссылка права & Ссылка & Ссылка Описание прав \\
\hline
\end{tabular}

В рамках разработки серверного приложения были сгенерированы REST контроллеры для обработки запросов для объектов [1]. Запросы обеспечивают операции создания, получения и удаления в соответствии с НТТР стандартами. Протокол для транспортировки - JSON.

Схематично серверную часть можно рассмотреть на рисунке 1. 


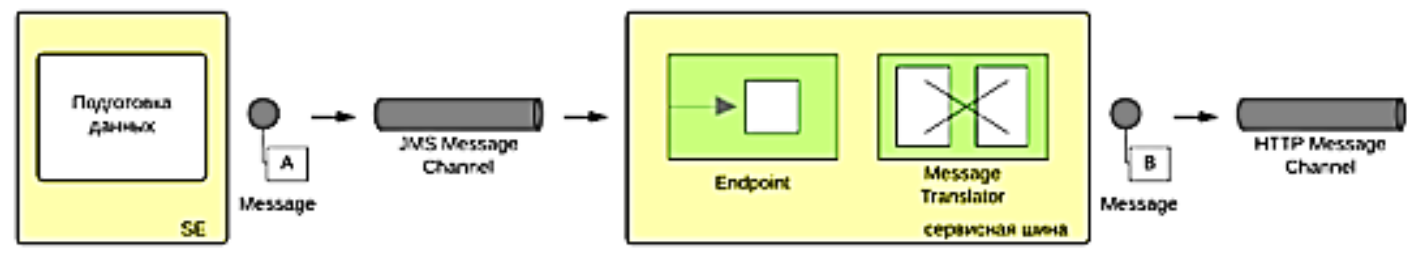

Рис. 1. Схематичное описание серверной части

Файловый сервис для хранения анкет и отзывов, который доступен по REST запросам.

Описание интерфейса строиться с применение инструмента JavaFX SceneBuilder. Оно позволяет легко работать с внешним видом приложения, генерируя в итоге html документ, описывающий элементы интерфейса и комбинируя их с внутренними обработчиками

В ходе работы над информационной системой следует использовать JavaFX приложение со списком студентов, получаемых напрямую с сервера 1C: Предприятие.

Таким образом в результате описания концепции разработки приложения определены основные требования для системы: спроектирована архитектура приложения, произведен обзор основных технологий, используемых при работе c JSON точками доступа, созданы прототипы приложения - сервер публикация и клиентское приложение, отметим что сервер производит публикацию обновлений базы данных 1C: Предприятие, а клиентская часть работает с базой данных и параллельно слушает обновления с сервера публикаций.

\section{Список литературь}

1. Spring Framework документация [Электронный pecypc]. - Режим доступа: http://www.spring-source.ru/docs_simple.php (дата обращения: 16.05.2017).

2. Новое в версии 8.3 (8.3.1, 8.3.2 и 8.3.3) [Электронный ресурс]. - Режим доступа: http://v8.1c.ru/overview/release_8_3/ (дата обращения: 28.03.2018).

3. Средства работы с JSON [Электронный ресурс]. - Режим доступа: http://v8.1c.ru/o7/201410json/ (дата обращения: 28.03.2018). 
4. Струбалин П.В. Учет и анализ движения и использования программных продуктов: Автореф. дис. ... канд. экон. наук / П.В. Струбалин. - Саратов, 2003. - 18 c.

5. Струбалин П.В. Учет и анализ движения и использования программных продуктов: Дис. ... канд. экон. Наук / П.В. Струбалин. - М.: 2002; Саратов, 2003. - C. $80-85$.

6. Струбалин П.В. Информационные технологии, обеспечивающие работу и безопасность систем электронного дистанционного обучения / П.В. Струбалин, Н.Б. Фролова // Информационная безопасность регионов. - 2015. -№4 (21). - С. 12-18.

\section{References}

1. Spring Framework dokumentatsiia. Retrieved from http://www.springsource.ru/docs_simple.php

2. Novoe v versii 8.3 (8.3.1, 8.3.2 i 8.3.3). Retrieved from http://v8.1c.ru/overview/release_8_3/

3. Sredstva raboty s JSON. Retrieved from http://v8.1c.ru/o7/201410json/

4. Strubalin, P. V. (2003). Uchet i analiz dvizheniia i ispol'zovaniia programmnykh produktov: Avtoref. dis., 18. Saratov.

5. Strubalin, P. V. (2003). Uchet i analiz dvizheniia i ispol'zovaniia programmnykh produktov: Dis., 80. M.: 2002; Saratov.

6. Strubalin, P. V., \& Frolova, N. B. (2015). Informatsionnye tekhnologii, obespechivaiushchie rabotu i bezopasnost' sistem elektronnogo distantsionnogo obucheniia. Informatsionnaia bezopasnost' regionov, 12.

Фатьянова Анна Алексеевна - канд. экон. наук, доцент Саратовского социально-экономического института (филиала) ФГБОУ ВО «Российский экономический университет им. Г.В. Плеханова», Россия, Саратов.

Fat'yanova Anna Alekseevna - candidate of economic sciences, associate professor at the Saratov socio-economic institute (branch) of Plekhanov Russian University, Russia, Saratov. 